\title{
Theorising disability: a practical and representative ontology of learning disability
}

\section{Abstract}

This paper contributes to the ongoing development of the theorisation of learning disability, focusing on the value of the ontological turn. We argue that while social theory has influenced understandings of disability within academia, particularly within disability studies, it has had a limited impact on the discursive and practical use of the term 'learning disability'. How 'learning disability' is constructed is of direct consequence to the lives of people with learning disabilities. Owing to this, we present a practical and representative ontology of learning disability in order to progress the ontological turn into everyday understandings of disability. To do this, disability theory is discussed, critically appraised and progressed. We then outline how this new theorisation could be re-contextualised within policy, with a view to further re-contextualisation into practice and the everyday. It is hoped that this paper will spark discussion regarding how the ontological turn can be used for change.

\section{Introduction}

This paper starts from the position that there is no one way of being a learning disabled person and that people given this label have diverse needs and abilities. This is by no means a radical or ground-breaking statement, but despite this, theory, policy and practice has long sought, and continues, to homogenise such people. How we think about disability and impairment and the terminology that is used to represent people with disabilities is value laden, politically imbued and socially constructive (Cluley, 2018). As Wendell tells us: 
'How a society defines disability and whom it recognises as disabled are of enormous psychological, social, economic and political importance, both to people who identify themselves as disabled and to those who do not but are nevertheless given the label' (Wendell, 1996 p.32).

Consequently, it is important that the philosophical starting point of such definitions is representative of the experience being defined. We should state here that we recognise that approaching learning disability in this way is most likely to be inaccessible for people with learning disabilities themselves (and indeed anyone who is not familiar with the philosophy or theory of social science). This potentially creates a conflict with the standpoint of 'nothing about us without us' that underpins much work in this field. However, it is imperative that terms that are used in everyday language and affect peoples lived experience are as representative and inclusive as possible. We argue that this is not currently the case, and that to understand this failing we need to attend to the philosophical underpinning of theorising learning disability, and the translation of this into the everyday. As Walmsley (2001) has argued, focusing solely on inclusivity can be to the detriment of theoretical development. While inclusion is a necessary and important ethos, a more interdependent approach is sometimes necessary.

In this context, it is important to recognise that, as a population group, people with learning disabilities have been found to be among the most economically and socially marginalised people in the UK. While this population group is diverse in terms of abilities and circumstance, taken as a whole they are not only more likely to live in poverty, but many have experienced bullying and abuse (EHRC, 2017). Few people with learning disabilities are in paid employment 
Theorising disability

(DWP, 2018; EHRC, 2017) and therefore, owing to high level of reliance on public services and welfare benefits, the lives and opportunities of many people with learning disabilities are heavily circumscribed by public policy. This may become particularly problematic when the theories upon which policies are (consciously or unconsciously) predicated do not adequately represent or reflect the realities of this highly heterogeneous population.

Within social policy in the UK, for example, people with learning disabilities are typically positioned as a homogeneous population group who are expected to make rational choices (Cumella 2008). Similarly, policy addressing learning disability in Australia and Canada also tends to represent people with learning disabilities in this way (Bigby, 2010; Bigby \& Ozane, 2009; Purcal et al, 2014; Werner, 2012). In this paper we specifically focus on UK social policy, however, the practical ontology that we propose can be applied across all policy addressing learning disability regardless of national origin.

Public policy in the UK and elsewhere, as well as much empirical research, continues to represent people with disabilities in terms of either the medical or social models of disability. Such representations continue despite the fact that these models have been argued to construct disability in ways that are problematic, particularly for those with learning disabilities (Shakespeare 2014, Hughes and Paterson 1997). Learning disability has historically been excluded, whether implicitly or explicitly, from theories of disability. Although many disability scholars now include learning disability when discussing the social model of disability (see, for example, Goodley, 2011), it has been argued that the social model of 
Theorising disability

disability leaves adrift those with the most severe physical impairments as well as those with many forms of cognitive impairment (Schildrick, 2015).

From the outset it should be understood that 'learning disability' is a term and experience that is inconsistently defined and represented (Cluley, 2018); it's meaning, and who is included, is ever-changing. The term learning disability is used in this paper because it is the term most commonly used in UK social care policy (Department of Health, 2001; Department of Health \& Social Care, 2018). Other terms used in the UK to refer to the same group of people include 'learning difficulty', which tends to be favoured by self-advocates and in special educational settings, or 'intellectual disability' and 'developmental delay', which are often used in clinical settings, reflecting the terminology used in psychiatric diagnostic manuals such as DSM V and ICD-11 (Higgins 2014). Other countries and other parts of the world (e.g. Australia, New Zealand and North America) may more often use the term intellectual disability. The point is not simply that that learning disability is represented differently in different contexts, but that the meaning behind the language has never been consistently defined. While a consistent approach to the use of language may not be achievable or desirable as differing terms can be useful, it is our contention that a consistent philosophical starting point that represents the realities of learning disability could contribute to improved policy and practices that better serve the diverse needs of people with learning disabilities.

This paper will argue that (learning) disability theory should be predicated upon a practical and representative ontology that can be contextualised into everyday understandings of 
Theorising disability

disability, including those of policy-makers. By this we mean that we are seeking to present a way of theorising (learning) disability that starts by asking 'what it is to be a person with learning disabilities?' rather than 'what is learning disability?'. To ask what is learning disability presupposes that there is one answer; to ask what it is to be a person with learning disabilities invites multiple answers. It is important to note that we ask this question at the philosophical level rather than the empirical level. Many research studies have sought to gain an insight into the experiences of people with learning disabilities (Fiztgerald and Withers 2013, Haigh et al 2013, and Povee et al 2014) and we do not seek to repeat this. Rather, we argue that a representative philosophical understanding of learning disability is lacking but needed. As outlined, philosophical discussion is often inaccessible to those without a prior understanding of it or indeed the cognitive capacity to make sense of it. In working through the philosophical detail, as academics who work hard to make sense of this, we hope to provide a practical ontology that will ultimately be transferable to the everyday. This is important because the way we understand things to be, and how we come to know this, predicate our understandings of the world.

Challenging inaccurate or unjust representations of disability and impairment is a mainstay of disability studies. Consequently, theorising impairment often emanates from a desire to represent those with impairments in the 'truest' way possible. However, it is important to recognise how the philosophical position of those doing the modelling or theorising will influence the discursive constructions they produce. For example: those approaching impairment from an essentialist perspective will favour discourses that infer objectivity, and a focus on the biological; those that adopt constructionist approaches will favour discourses 
Theorising disability

that pertain to the social, the environmental and the cultural; and those that approach from a deconstructionist perspective will favour discourses that invoke the body and the flesh as non-dualistic, experiencing phenomena. The point is that each theory or model constructs disability in different terms. The language used to refer to disability, therefore, can differ depending on the model/theory being used.

The philosophical position this paper adopts is akin to that of theorists progressing the 'ontological turn' within disability studies (Goodley 2014; Schildrick 2015; Feely 2016). The ontological turn developed first in cultural anthropology with the rejection of the idea that culture is singular (Palecek and Risjord 2012). At its simplest, the ontological turn can be understood as a rejection of the assumption that there is an automatic or necessary division between the natural and the social (Heywood, 2017). In taking this approach, the ontological turn repositions 'things' and ways of seeing them as multiple and fluid rather than natural and static. In terms of disability studies, the ontological turn moves the disabled body away from discourses that assume it to be of fixed nature and instead considers it as both heterogeneous and changeable. In this way it becomes possible to acknowledge material bodies, and what they can or cannot do, without fear of a return to essentialism. The learning disabled body is therefore theorised in this paper to be a product of ongoing and everchanging biological and social interactions (including: objects, culture, environment, discourse and economics).

While conceptualisations of disability have recently taken an ontological turn, and there has been positive progress in the theoretical representation of people with disabilities within 
Theorising disability

disability studies, there is as yet little evidence of this influencing the lives of people with learning disabilities through a changed basis for policy-making. With this in mind, this paper aims to further ontological discussions of disability in order to encourage the practical integration of theory, as a discourse at work, into the everyday. To do this, in section 1 we discuss disability theory and set out a practical, representative and fluid ontology of disability, based on Deleuze and Guattari's (1987) concept of assemblage. In section 2, policy examples of the intertextuality of theories as discourses at work are provided to highlight the theory/practice gap that this paper seeks to overcome. Finally, recommendations are made for the active application of theory into policy and practice. It is hoped that our suggestions will spark discussion regarding how the ontological turn can be used for practical change.

\section{Theorising learning disability: the learning disabled body}

A wide variety of models and theories have been put forward in order to make sense of disability, including: the social model (Oliver 1990), the medical model (Arehart 2008), social constructionism (Rapley 2004), critical realism (Shakespeare 2014), feminist disability theory (Morris 1997), phenomenology (Hughes and Paterson 1997, Hughes 2004, Maldenov 2014), post-structuralism (Clegg et al 2017, Schildrick 2016, Feely 2016, Corker 1998), symbolic interactionism combined with embodiment theory (Coleman-Fountain and Mclaughlin 2013) and dis/ability studies (Goodley 2014). Of these models and theories, the social model and the medical model provide the two dominant, contrasting, constructions of disability (Shakespeare 2014). While feminist disability theory, poststructuralism, phenomenology and social constructionism are well represented within academic research, only the social and the 
Theorising disability

medical models have visibly penetrated policy, practice, everyday language and public perception (Shakespeare 2014).

Unfortunately, the medical and social models both - albeit in different ways - misrepresent people with disabilities through their construction of impairment as an individual, biological issue (Shakespeare 2014, Hughes and Paterson 1997). The medical model does this explicitly by positioning disability as simply a pathological category that can be medically recognised in individual bodies (Arehart 2008). By contrast the social model does this implicitly, by dismissing the body as an unnecessary consideration (Hughes and Paterson 1997). Underpinning both discourses is a dependence on a Cartesian conception of the self, with its inherent mind-body-dualism.

Descartes' Cogito (1640) separates the self from the body; the legacy of which is found within both essentialist and social constructionist approaches to the body (Hughes and Paterson 1997). For Descartes, the body functions mechanistically, independent of the self which is located in the mind or the soul. In this way the body is presented as a material object of secondary importance to the mind and knowledge is constructed as a reaction of the self to pre-existing external objects, including bodies (Edwards 1998). Mind-body dualism has become a hegemonic part of Western thinking: accepted tacitly and uncritically (Damasio 1994). Added to this, where cognitive ability/rational action is highly prized, Descartes' mind/body dualism has morphed into a brain/body dualism. The mind and the brain have become inseparable to the point where the brain is no longer recognised as an organ of the body (which may be impaired) but is instead thought of as being a 'mind' which is separate 
Theorising disability

from the body. Within the social model, moreover, just as in Descartes' dualism, the body is the site of impairment and the mind is the site of resistance. This is reflected not only in the social model's call for disabled people to unite as self-advocates for the removal of disabling barriers, but also in the implicit exclusion of learning disability as an impairment that challenges the mind/body and impairment/disability dualisms that the model is hinged upon. The cognitive ability required to establish a collective identity and work towards the removal of disabling barriers is not thought of in terms of bodily action but is thought of in terms of the mind or the self. The normalisation of such a perspective is reflected in how learning disability is constructed in social policy. People with learning disabilities are presented homogeneously as people who can make their own choices, be fully and equally involved in policy and research processes and ultimately function in the same way as those who are cognitively able. While this may be possible for some people with learning disabilities it is certainly not the case for all.

The development of post-structural, phenomenological, symbolic interactionist and feminist perspectives have repositioned the body within academia (Watson and Cunningham-Burley 2001) and the Cartesian epistemology is now widely criticised (Turner 2008, Watson and Cunningham-Burley 2001, Burkitt 1999, Edwards 1998, Leder 1990, Barad 2008). While such critiques have been readily applied to medicine (Leder 1990), mental ill health (Foucault 2001), women's health (Butler 1993, Garland-Thompson 2003, Wendell 1996) and perceptions of disability in general (Wendell 1996), there has been less interest in their application to learning disability (but see Edwards 1998, Maldenov 2014, and Feely 2016 for examples). This is despite the fact that mind/body dualism is particularly problematic for 
Theorising disability

learning disability, due to the cognitive and chronic nature of the impairment. From this starting position, we now turn towards the task of discussing and mapping the progress that has been made in theorising disability at the ontological level.

\section{Towards a representative ontology of learning disability}

\section{A phenomenological approach}

In order to move beyond Cartesian dualism, a number of theorists have looked to phenomenology to provide a way forward (Hughes and Paterson 1997; Edwards 1998). This is because phenomenology reclaims the body while dissolving dualistic conceptions of the body as an object. Phenomenology, moreover, is what Nettleton and Watson (1998 p.4) call an 'embodied perspective'. Indeed, Merleau-Ponty (1964), called for a rethinking of perception, not as something that impacts internally as a reaction to external objects, as in Cartesianism, but as something that is embodied. In his words, the point of phenomenology is to 're-establish the roots of the mind in its body and in its world' (Merleau-Ponty 1964 p.3).

The phenomenological body contains the mind and body as one; this non-dualistic body is positioned in the world and represents the site of perception (Williams and Bendelow 1998). In this way, the body is ontologically repositioned as the locus of experience, and because the body is positioned in the world, embodied perception is always situated (Morgan 2008). The body, thereby, is not reduced to a pre-social object but is just as much part of the world as it is constructed by the world (Nettleton and Watson 1998). Merleau-Ponty's concept of the 'sentient-body-subject' positions bodies as sites of meaning via individual perception and 
Theorising disability

experience within a shared world (Williams and Bendelow 1998). As Edwards (1998 p.53)

tells us, 'the self as subject, is not construed as something purely mental. Rather it is understood as necessarily embodied. The self as an acting subject is inseparable from and identical to the body'. This body, moreover, is formulated as an active agent.

The language of the social model (in that it differentiates between impairment and disability) has been used to apply a phenomenological perspective to the construct of disability (Hughes and Paterson 1997). Indeed, Hughes and Paterson (1997 p.335) tell us that 'impairment and disability meet in the body not as the dualistic clash of inner and outer phenomena, but insofar as impairment structures perceptions about disability and disablement is part of the felt world'. In this way, phenomenology allows the impaired body to both view the world and perceive disablement and this allows the body to be reclaimed as part of disability rather than discarded as secondary. As Hughes and Paterson (1997 p.335) further state 'in this context impairment escapes the habitual. It enters the realm of signification and its meaning arises from a symbiosis of personal embodied knowledge and abstract cultural beliefs'. In other words, learning disability is integral to how people with learning disabilities experience the world, in that it is lived as a bodily experience that is both felt and socially constructive, by virtue of the body's outward facing orientation within the world.

Building on this, Edwards (1998) makes an argument for the use of the phenomenological body when thinking about disability and seeking to escape the dominance of mind/body dualism. For Edwards (1998), phenomenology's conception of the body - as an integration of mind and body that positions the self as an embodied subject - allows disability to be 
Theorising disability

thought of as constructive. The phenomenological body can, therefore, both represent and know the world; as Edwards (1998 p.54) states, 'the nature of the subject's experience is determined by the nature of the body'. In this way phenomenology allows us to think about experience as wholly embodied, which further allows the development of the idea that learning disability is not homogenous (as it is often portrayed to be) but is dependent on individual bodies and their specific histories of social interaction.

Despite this, the application of phenomenology as a research practice rather than a philosophy has also been subject to criticism (Morgan 2008; Williams and Bendelow 1998). If Hughes and Paterson's (1997) argument is applied to learning disability policy and practice, phenomenology is revealed as an ableist discourse, rooted in the assumption that nondualistic bodies are non-learning disabled. As highlighted, Hughes and Paterson (1997 p.335) use a phenomenological approach to argue for a 'realignment between, body, self, and society' that they claim results from the presence of impairment and the ability of the impaired body to experience disability and therefore make sense of the impaired body's position in the world. As a philosophy this sounds 'plausible' (Edwards 1998). However, phenomenology implicitly constructs the experiencing body as cognitively able. Many people with learning disabilities, particularly those with the highest support needs are not cognitively able to make sense of their learning disability in the way phenomenology prescribes of experiencing subjects. Added to this, in reality, the experiences of learning disabled bodies situated in the world, and the meanings that these experiences create, are seldom taken into account (Walmsley 2001). 
Theorising disability

\section{A feminist approach}

Post-structuralist feminist perspectives on bodies also go some way towards untangling the problem that a phenomenological perspective creates when applied to learning disability. For example, while Butler's (1993) Bodies that Matter is concerned with the female body, her primary argument - that regulatory power constructs bodies and that in doing so a constitutive outside is also created - could just as easily apply to any other marginalised body, including the learning disabled body. Butler (1993, p.1) states:

'the category of sex is from the start, normative; it is what Foucault has called a regulatory ideal. In this sense then sex not only functions as a norm but is part of a regulatory practice that produces the bodies it governs, that is whose regulatory force is made clear as a kind of productive power, the power to produce - demarcate, circulate, differentiate - the bodies it controls'.

If Butler's category of sex is replaced with ability, then disability can be seen as a constitutive outside, framed by Butler as an 'abjected outside, which is after all, inside the subject as its own founding' (ibid p.3). The inside subject (the able body), is dependent upon the existence of an outside (the disabled body). While phenomenology and post-structuralism represent different ways of seeing the world, Butler's idea of a constitutive outside can be used to explain the problematic application of phenomenology to learning disability. Phenomenology, while asserted as non-dualistic, does not account for the constitutive outside that learning disability represents to the phenomenological embodied subject. 
Theorising disability

This said, Butler's concept of bodies is also not without problems. Post-structuralist accounts have been criticised for rendering the body 'both everywhere and nowhere' (Williams and Bendelow 1998 p.1). For Butler, the material body is produced and reproduced through the power of discourse.Consequently, Bigwood (1991 p.59) tells us that 'the poststructuralist body... is so fluid it can take on almost limitless embodiments. It has no real terrestrial weight'.

As McLaughlin and Goodley (2008) note, other feminists addressing disability have sought to highlight the relationship between the material and the discursive in ways that avoid these criticisms. Wendell (1996), for example, draws on ableist constructions of the everyday and finds parallels with feminist approaches to the body. For Wendell (1996) the feminist argument that gender is socially constructed as a result of physical/material differences between females and males can be translated to disability, in that disability is constructed as a result of differences between the disabled and the non-disabled. For Wendell (1996), however, the body cannot be entirely socially or culturally constructed. Instead, Wendell thinks of the biological and the social as interactive agents that construct bodies and therefore, disability, stating:

'I believe that in thinking about the social construction of disability we need to strike a balance between, on the one hand, thinking of bodies' abilities and limitations as given by nature and/or accident, as immutable and uncontrollable, and on the other hand, thinking of them as so constructed by society and culture as to be controllable by human thought, will and action'. (Wendell, 1996 p.45) 
Theorising disability

To acknowledge that not all social change can eliminate bodily difference, rather than seeming defeatist, is both refreshing and plausible; this allows the body both 'limits and weight' (ibid, p.168).

\section{Moving towards a fluid ontology}

What is useful about both phenomenological and feminist approaches is that emotions, senses and feelings are recognised as part of the body. Unlike the Cartesian separation of the mind from the body, and in turn the brain from the body, within these approaches issues often considered to be of the mind are constructed as embodied. As Nettleton and Watson (1998 p11) tell us, 'the concepts of the lived body and the notion of embodiment remind us that the self and the body are not separate and that experience is invariably, whether consciously or not embodied'. Relatedly, Coleman-Fountain and McLaughlin's (2013) application of symbolic interactionism and theories of embodiment to the understanding of impairment seeks to explore how certain performances of embodiment become known to be different. This lens can be usefully applied to understandings of learning disability in that symbolic interactionism stresses the role of social encounters in the production of selves while embodiment theory provides the body with a material but non-dualistic reality. The combination of these approaches allows impairment, framed as 'what bodies can do' (Coleman-Fountain and McLaughlin, 2013 p.133), to be seen as a relationship between material bodies and social interactions. Unlike a post-structuralist approach, therefore, the materiality of the body is considered to be an essential factor within impairment. Indeed, the

authors state 'the way in which bodies look and function are significant in informing social 
Theorising disability

interactions and are fundamental in deciding how bodies and persons 'fit' within normative frameworks of understanding' (ibid, p.139).

From this position, the importance of the body in the understanding of impairment is threefold (Coleman-Fountain and McLaughlin, 2013). First, bodies that exist in the world are argued to be present within discursive practices. Here they give the example of the diagnosis of visual impairment and state 'to talk of a visual impairment implies something about the capacity of that body to see' (ibid, p.139). Second, the body and what it can do is positioned as essential to the understanding of why some bodies are stigmatised and others are not. Third, how bodies perform is identified as playing a key role in social interaction and the production of identity. This simultaneous focus on what bodies can do and their role in social interaction allows learning disability to be seen in terms of a co-constitutive relationship between the material and the social and thus avoids the dualisms associated with the medical and social models.

Similarly, when writing about pain, other authors have highlighted the difficulties encountered by approaches that render the material body invisible; they call for a sociological approach that embraces the body as the site of feelings and emotion in order to '(re)locate the embodied individual within the broader sociocultural contexts of meaning and action, thereby freeing pain from exclusive biomedical jurisdiction' (Williams and Bendelow 1998 p.158). What is interesting about this approach to pain is that it recognises the biological origins of pain yet avoids dualistic dominance by asserting pain, its origins and its experience, as embodied. In this way the lived body can be ontologically thought of as a material entity 
Theorising disability

while also being epistemologically thought of as a culturally orientated one. As Bendelow and Willaims $(1998,0.210)$ state, epistemology of culture and social norms fills 'the existential space between the immediate embodiment of disease as brute materiality and its meaning laden character as human experience'.It is important to note that this suggestion is not hinged upon the dominant Cartesian conception of biology. When outlining their approach to biology, they tell us that: 'to claim a biological foundation for the body does not necessarily imply reductionism if the very nature of biology itself is fundamentally rethought within the social sciences. Biology is not simply a limit or constraint. Rather it provides the active basis and transformative potential of our embodied being in the world' (Williams and Bendelow 1998 p.211).

Another useful mechanism when seeking to give weight to the body without a return to essentialist criteria is Deleuze and Guattari's (1987) concept of rhizomatic assemblages, as advocated by Shildrick (2015), Feely (2016, although from a Delandian perspective) and Goodley (2007). For Deleuze and Guattari all phenomena and experience are part of everchanging interrelationships of rhizomatic assemblages. Referring back to nature to explain this, Deleuze and Guattari (1987) draw on the analogy of a rhizomatic root system found in grass, bamboo and orchids for example. Instead of having a beginning or an end, rhizomes begin in the middle. They connect to other rhizomes and continue in this way to progress in the face of change, such as being severed by a spade (Cluley, 2019). Importantly this growth is not simply a case of the one becoming two. A rhizomatic assemblage is comprised of multiple and changeable elements that exist in a flexible relationship with one another, and just as this can create a root system, so in Deleuze and Guattari's analogy it can create a 
Theorising disability

thing/experience/event. In this way essence is rejected and fluidity, multiplicity and change is embraced. Important to the argument presented here, such assemblages have the potential to both create and recreate identities as well as bodies, objects and events (Nail 2017).

The concept of assemblage provides the underpinning for thinking about the notion of becoming, which has been linked by learning disability theorists to wider notions of 'being, and belonging' (see Goodley 2007 and Feely 2017). Like an assemblage, a becoming is not a linear process with a beginning or an end, nor is there a teleological destination; rather it is rhizomatic in nature, it happens between things, it is a state of being in-between, and it produces only itself (Goodley 2007). For Deleuze and Guattari (1987) becoming is central to understanding our being in the world, and the social phenomena, agents and objects that are part of this. Moreover, things, events, identities, experiences etc can be both what Deleuze and Guattari refer to as molar (majoritarian) and molecular (minoritarian). A molar identity is a state of being, it is a whole, whereas a becoming is framed by Deleuze and Guattari (1987) in terms of having molecular status.

If we think about disability in terms of becoming we can see that, at this moment in time, ability is what Deleuze and Guattari frame as a molar (primary) identity and disability is its difference, its molecular outside. When talking about 'becoming' Deleuze and Guattari (1987 p.292) state 'there is no becoming-man, because man is the molar entity par excellence, whereas becomings are molecular...man constitutes the majority, or rather the standard on which the majority is based: white, male, adult, rational etc'. Similarly, the predominant way 
Theorising disability

of seeing the body, in terms of a mind/body spilt, can readily be coupled with neoliberal values to create a powerful, molar, discourse. For Deleuze and Guattari (1987), the molecular always has the potential for change by way of being both connected and fluid, stating 'becoming is a verb with a consistency all its own; it does not reduce to, or lead back to, appearing, being, equalling or reducing' (1987 p.263). In this way, molecular learning disabled bodies are afforded power.

Importantly for the argument made here, rhizomatic assemblage and becoming provide a fluid ontology from which to make sense of the world. Within an assemblage, no one element (material, physiological, environmental etc) is prioritised; rather all factors are considered to be without essence and to have the potential for change and becoming (Deleuze and Guattari 1987). The emphasis is that everything is fluid, nothing is final. Consequently, things, events, objects, bodies etc, can only be known as a snapshot of what they are at a moment in time and because of this all assemblages are unique (Nail 2017). As Shildrick (2015 p.16) states, Deleuze and Guattari's approach lends itself to the idea of 'co-corporeality, where bodies are not just contiguous and mutually self-reliant but entwined with one-another'. In this way the essentialist history of biology can be removed as a primary focus and biology can be repositioned as an evolving phenomenon whose existence is dependent upon a multitude of contextual and changing factors.

Using this approach, as with Williams and Bendelow's example of pain, learning disability can be seen as both a biologically and socially embodied state: 'stripped of its ideological baggage, biology provides a radical critique rather than justification of existing social arrangements' 
Theorising disability

(Williams and Bendelow 1998 p.212). This is useful because it both avoids and rejects dichotomous thinking. If learning disability is thought about as an assemblage, biology is stripped of its essence and repositioned as evolving and relational. While the biological is recognised, it is not prioritised. Further to this, the biological is repositioned as something that can be thought about differently. The body is not positioned as a Cartesian object, but as an active subject. As Thomas (2004, p.59) states, 'such an ontology can, and should, hold to the position that this biological substrata is always and everywhere overlaid with socially constructed ideas about the body'.

Of particular value to theorising disability through the lens of Deleuze and Guattari's concept of rhizomatic assemblage is that people with disabilities themselves can be fully included as active agents of change. While all assemblages are necessarily different, Deluze and Guattari (1987) assert that all assemblages have three certain characteristics - the abstract machine, the concrete assemblage and personae. Personae are the active agents within an assemblage. Rather than being thought of in terms of the rational self-knowing agent, Deleuze and Guattari position the personae in terms of the third person (Nail 2017). The personae is an interdependent collective. Cognitive ability, therefore, is neither explicit nor implicit in this conceptualisation, rather interdependency and collective action is the focus. This both affords the learning disabled body power and also allows policy makers to adopt a radically heterogeneous understanding of learning disability. 
Theorising disability

Based on this theoretical review and discussion, we next present our emergent theorisation of learning disability in order to provide an ontological framework that can be practically recontextualised into the everyday.

\section{Re-theorising learning disability}

In order to ensure that term learning disability (and indeed other commonly used terms) are representative and inclusive, it is first and foremost necessary to uncouple biology from its essentialist hegemony. The rejection of dualisms, via the reconstruction of biology and the positioning of bodies as both ontologically material and epistemologically embodied, allows learning disability to be located in an individual body as a biological construct without recourse to the medical model. It is important here to think of biology in non-dualistic terms: to think of biology, as Thomas (2004) encourages us to, as socially layered; as Feely (2016) advocates, as without essence; and as Williams and Bendelow (1998) state, as without limit or constraint but rather as platform for embodiment. In constructing biology in this way, biology becomes not something to be ignored or feared as in the social model but, as Williams and Bendelow (1998) argue, a radical critique of Cartesian dominance. Furthermore, it allows the social to have a place within the body and vice versa.

In this way learning disability is represented here as an ever-evolving assemblage, where no one factor is prioritised or afforded the status of an 'essence'. Seen through the concept of an assemblage, the learning disabled body is materially present in a non-essentialist relationship with a multitude of other factors, phenomena, experiences and discourses, all of 
Theorising disability

which serve to produce the lived experience of learning disability. Importantly, assemblages are not static, they can be different in different situations and for different people, allowing disability to be recognised as the heterogeneous, relational, experience that it is. As Shildrick concisely states, 'assemblages matter to critical disability studies as they provide a way of thinking differently about embodiment, a way that avoids the hierarchies of value that mark modernist thought' (ibid, p.21). It is imperative that learning disabled bodies and the ways of being that they present are afforded importance when seeking to understand learning disability; conceptualising disability as a rhizomatic assemblage, allows this to happen.

While theoretical progress within disability studies has allowed this open and representative approach to be reached, such an approach has not yet filtered into policy. Indeed, outdated discourses of disability continue to predominate. With Wendell's statement in mind (see opening paragraph), this is of particular significance to the lives of people with learning disabilities.

\section{The construction of learning disability in policy}

Having examined the possibility of retheorising learning disability, we next turn to the repreentation of learning disability in policy and how our retheorisation can practically improve this. Indeed, this paper aims ultimately to help improve the way learning disability is represented in policy, in England and elsewhere. In doing so, we draw on examples of English policy whose underlying ethos is echoed in other industrialised nations. 
Theorising disability

Learning disability is seldom the subject of exclusive policy initiatives and there have only ever been three learning disability-specific English White Papers: Mental Handicap: Progress, Problems and Priorities (DHSS, 1971); Valuing People: A New Strategy for Learning Disability for the $21^{\text {st }}$ Century $(\mathrm{DH}, 2001)$ and Valuing People Now: a new three-year strategy for learning disabilities (DH, 2009). In replacing the term 'mentally handicapped' with the term 'learning disability' and giving an outward show of embracing the principles of the social model, the Valuing People White Papers changed the tone of English learning disability policy (Burton and Kagan 2006).

Despite the changed language, however, people with learning disabilities continued to be characterised as a broadly homogenous group and determinedly represented in accordance with principles of liberal citizenship (Redley and Weinberg 2007). The implication is always that, given the opportunity for independence, the voice for change and the freedom to choose, people with learning disabilities can be active citizens just like anyone else. Such an approach is aided by the discursive influence of both the social and medical model of disability. To explore this argument further, examples from both Valuing People (DoH 2001) and the more recent Care Act 2014 Statutory Guidance (HMSO 2017) will be considered. It is noted that the Mental Capacity Act (2006) would also provide a useful case to be discussed here but for reasons of space this has been omitted.

The Valuing People principles of rights, choice, independence and social inclusion contain echoes of the neoliberal concern with individual rights, market choice, and independence from the state (Burton and Kagan 2006; Fyson \& Cromby, 2013). While this may be politically 
Theorising disability

disagreeable for some, our concern here is with the choice-making individual which such policies assume to exist. As Goodley (2014 p.28) highlights, 'the functioning neoliberal self is an able bodied and minded one', but homogenising selves in such a way is problematic for some people with learning disabilities. Within Valuing People choice is presented as equally applicable to all and equally achievable by all: 'this includes people with severe and profound disabilities who, with the right help and support, can make important choices and express preferences about their day to day lives' (DoH 2001 p. 24). Morally loaded statements, such as this, appear to be irrefutable. Who would deny a person the equal right to choose, to take control of their own lives, to achieve social acceptance? It is necessary, however, to question the extent to which an approach to social care that imposes personal responsibility for life choices is applicable to all people with learning disabilities (Redley and Weinberg 2007). As has been suggested, 'if people [with learning disabilities] were able to be fully independent and to make important life choices without support then they would not be receiving statefunded services in the first place' (Fyson \& Kitson, 2007).

While its embrace of social model principles allowed Valuing People, and similar policies in other countries, to be seen as pioneering new approaches to learning disability (Burton and Kagan 2006), in reality there is a profound disconnect between the social model and the neoliberal approach to governance which these policies also implicitly embrace. The social model is based upon collectivist approaches and seeks equality, by contrast neoliberalism is driven by competitive individualism and unequal outcomes are accepted as inevitable perhaps even to be welcomed. 
Theorising disability

It must be remembered, moreover, that the medical model of disability is an active part of the social model, vis its disability/impairment spilt. In this way the social model continues to retain key elements of the individualistic medical model and therefore lends itself to the discourse of neoliberalism. At the same time, the medical model of disability does not challenge neoliberal ideology and allows it to dominate. Indeed, both neoliberalism and the medical model are underpinned by a commitment to Cartesian logic. The location of disability within individual bodies is convenient for a government that wants its citizens to take responsibility for themselves. Under the medical model, disabled citizens can be shaped and disciplined in a way that disabled citizens as constructed by the social model cannot.

It is within social care policy for people with learning disabilities that the neoliberal agenda becomes most obvious and its impact on the construction and (mis)representation of learning disability is further evidenced. The type of persons who English policymakers believe need care services becomes apparent from reading the principles which underpin the Care Act; these include 'the importance of beginning with the assumption that the individual is bestplaced to judge the individual's well-being' (Care Act, 2014, s.1 (3) (a)). This is translated into the prevailing orthodoxy that the 'best' way to provide social care services for adults, including adults with learning disabilities, is via individual budgets and self-directed support. Indeed, the Care and Support Statutory Guidance (Department of Health and Social Care 2018) that accompanies the Care Act 2014 is predicated on a discourse of 'ownership', 'control', 'choice' and 'independence' - concepts within which the mind/body dualism is implicit. The section detailing 'care and support planning' states, 'the person must be genuinely involved and influential throughout the planning process and should be given every 
Theorising disability

opportunity to take joint ownership of the development of the plan'. Again, such rhetoric appears irrefutable due to its foundation of popular moral values.

Both Valuing People and The Care Act 2014, however, are illustrative of what Carlson (2001) refers to as 'cognitive ableism'. Cognitive ableism is a product of accepted and unconscious ways of understanding learning disability, characterised by the reification and location of disability within certain individuals (as seen in the Valuing People definition and general approach to support), and the privileging of cognitive ability over all other characteristics. Carlson (2001) frames cognitive ableism as a product of social and political circumstance. In this way learning disability is constructed as a homogenous way of being, located within individual bodies, consistent with essentialist perceptions of disability. As such, these bodies can be circumscribed into the discourse of liberal citizenship, they can be bodies who can make the right choices and live independently. Neoliberalism has normalised the desire for similarity (Goodley, 2014) and so people with learning disabilities are presented as a homogenous group of rational choosers, blurring the difference between people with and without learning disabilities to the point where difference is ignored. While this provides moral shelter (Pilnick et al, 2010) by avoiding defining people by their differences, reduced cognitive ability remains an inherent property of learning disability that needs to be accounted for.

The representation of people with learning disabilities in this normalising way explicitly excludes a significant number of people with learning disabilities. Cumella's (2008) critique of Valuing People clearly shows the implicit neglect of people with the highest support needs; 
Theorising disability

he notes how 'the review of currently available data suggests that the person-centred assessments proposed in the white paper as a means of enhancing choice for people with a learning disability have probably affected only a minority of those eligible, and may have differentially excluded the most disabled' (Cumella, 2008 p.183). Other evidence supports this position. For example, Learning Disability Partnership Boards, established to involve people with learning disabilities in local decision-making, often excluded and failed to represent those with the highest support needs (Fyson, 2015). Consequently, learning disability is not only inaccurately represented in social policy rhetoric, it is also inappropriately represented at the expense of those with the highest support needs.

It is through the analysis of such policies that the dominance of a Cartesian approach to the body can be seen. As outlined, such an approach does not reflect the diverse realities of learning disability. However, Cartesian logic 'is so deeply entrenched within Western culture that it has taken on a common sense appeal. It seems inescapable if not downright natural' (Barad, 2008 p.806).

Indeed, the neoliberal foundation of many social care policies, in combination with a social/medical model discourse, has a direct influence on how learning disability is constructed in policy, practice and lay language, thus furthering the normalisation of a dualistic approach to the body. It nevertheless remains difficult to find a place for learning disability within the discourses of either the medical or social models. Just as the medical model's imposition of ways of seeing and experiencing disability is problematic for people with learning disabilities, so too is the social model's claim to speak on behalf of all disabled 
Theorising disability

people and its neglect of bodily experience. Consequently, people with learning disabilities find themselves (mis)represented in policy. Such policies, and the practices that they facilitate, would benefit from a consistent philosophical grounding that can provide respectful and truthful representations of people with learning disabilities which acknowledge the heterogeneous and fluid nature of the experience/reality of learning disability.

\section{Conclusion: The recontextualisation of theory into practice}

The argument presented here, that the concept of assemblage offers an inclusive, collective, progressive and beneficial way of thinking about disability that rejects essentialism and offers hope, has now reached a difficult transition - that of discussing how such theory can be recontextualised into the everyday in order to work towards change.

It is relevant to note that, outside of academia and disability movements, the model or theory of disability being used in any circumstance is unlikely to be a conscious undertaking and is more likely to be a reflection of how aspects of the medical and social models of disability have become part of normative social values in many industrialised nations. For example, it is now commonplace to think of environmental or physical barriers as disabling. It is unlikely that anyone would disagree that steps into shops, workplaces etc. make access for wheelchair users difficult, or that libraries with only small print books are inaccessible to visually impaired people. This currently-normative way of seeing disability reflects the influence of the social model of disability as a discourse at work. Equally, the medical model remains apparent when other everyday conceptions of disability are considered. For example, it is socially expected 
that a parent of a child with substantial physical, sensory or cognitive developmental delay will seek diagnosis and advice from medical professionals; failure to do so would be widely viewed as bad parenting. Models and theories of disability, therefore, are perhaps better understood as normative discourses at work within particular settings.

A Deleuzian approach to ethics can be used to question the efficacy of the normative discourse of choice that currently dominates within learning disability policy. Clegg et al (2017) draw on Braidotti's (2012) notion of a triple shift that occurs if Deleuzian ethics are applied to the everyday. This involves: reframing individual action in terms of relational and collective achievement; moving away from relying on moral rules to structure action towards practical ethical action; and progress from moral judgement of those who deviate from social norms in favour of embracing the relationships between people and the affirmation this can bring. In doing so, they propose two possible developments for learning disability practice a focus on how rights and relationships can co-exist and a focus on research addressing learning disability practice using a relational perspective (Clegg et al, 2017).

Developing their latter suggestion through the lens of the concept of assemblage, we agree that perhaps the first step towards removing the molar identity of mind/body dualism that underpins so many of the problems within theories of disability is to start with the empirical research upon which social policy is often based. If the ontological framework proposed here was applied by academics and then policy-makers, disabled bodies could be represented as becoming-bodies, whereby all the elements that make up their becoming are both without essence and hold the potential for change. In this way, all bodies can be represented and all 
Theorising disability

voices (needs) can be heard. By framing the agents involved in an assemblage in terms of personae, a platform for change could emerge.

In thinking of the agents involved in an assemblage as interdependent, the general logic of assemblage includes all who are involved, regardless of ability. The voices of self-advocates and Government Ministers thereby become equally valid. If policy-making were to be conducted through the lens of the logic of assemblage, then the voices of those who are least heard would have a fighting chance of representation. Or, at the very least, policy makers may be encouraged to consider and explicitly recognise who their 'inclusive' policies are still excluding, and in this way may become more aware of the needs of the heterogeneous continuum of people with learning disabilities.

With the concept of assemblage also comes optimism, for here everything is always subject to change and the molecular is always in a state of becoming, affording it power. The current pervasiveness of the social model (although problematic) is an example of this. As Shildrick (2015, p.23) asserts, in an assemblage the molar and the molecular come together to challenge dichotomies and 'mobilise unexpected and productive connections between disparate orders of becoming'. In this way, even hegemonic, molar discourses such as neoliberalism and mind-body dualism have the potential to be disrupted.

While this paper has been written by academics who do not have a learning disability it is hoped that the framework we have provided can facilitate a more inclusive approach to 
understanding learning disability. It is further hoped that this paper will spark the beginnings of discussion of how, practically, to recontextualise the ontological turn in the everyday. Responses, developments and challenges are welcome.

\section{References}

Areheart, B. (2008) When disability isn't 'just right': The Entrenchment of the Medical Model of Disability and the Goldilocks Dilemma, Indiana Law Journal, 83 (1) 181- 232

Bigwood, C. (1991) Renaturalising the Body (With a little help from Merleau-Ponty), Hypatia: A Journal of Feminist Philosophy, 6 (3) 54-73

Bigby, C. (2010) A Five-Country Comparative Review of Accommodation Support Policies for Older People with Intellectual Disability, Journal of Policy and Practice In Intellectual Disabilities, 7 (1) 3-15

Braidotti, R. (2012). Nomadic Ethics. In D. W. Smith \& H. Somers-Hall (Eds). The Cambridge companion to Deleuze (pp. 170-197). Cambridge: Cambridge University Press.

Burton, M. and Kagan, C. (2006) Decoding Valuing People, Disability, Disability \& Society, 21 (4) 299-313

Burkitt, I. (1999) Bodies of Thought, Embodiment, Identity and Modernity, London: Sage

Butler, J. (1993) Bodies That Matter. On The Discursive Limits of Sex, New York: Routledge

Carlson, L. (2001) The Faces of Intellectual Disability, Philosophical Reflections, Bloomington: Indiana Press

Clegg, J., Murphy, E. and Almack, K. (2017) Liberal individualism and Deluzian rationality in intellectual disability. Philosophy, Psychiatry and Psychology, 24 (2) 359-372

Cluley, V. (2018) From "Learning disability to intellectual disability"-Perceptions of the increasing use of the term "intellectual disability" in learning disability policy, research and practice. British Journal of Learning Disabilities, 46 (1) 24-32

Cluley, V. (2019) Becoming-care: reframing care work as flesh work not body work. Culture and Organization https://doi.org/10.1080/14759551.2019.1601724

Coleman-Fountain, E. and McLaughlin, J. (2013) The interactions of disability and impairment, Social Theory \& Health, 11 (2) 133-150

Corker, M. (1998) 'Disability Discourse in a Post Modern World', in Shakespeare, T., (ed) (1998) Disability Reader, Social Science Perspectives, London: Continuum. 
Cumella, S. (2008) New Public Management and Public Services for People with and Intellectual Disability: A review of the Implementation of Valuing People in England, Journal of policy and practice in intellectual disabilities, 5 (3) 178-186

Damasio, A. (1994) Descartes' error: emotion, reason, and the human brain. London: Random House

Department of Health \& Social Care (2018) Care Act Statutory Guidance, updated 12 February 2018 https://www.gov.uk/government/publications/care-act-statutory-guidance/care-andsupport-statutory-guidance

Department of Work and Pensions (2018) Family Resources Survey 2016/17 https://assets.publishing.service.gov.uk/government/uploads/system/uploads/attachment data/file/692771/family-resources-survey-2016-17.pdf

Department of Health (2009) Valuing People Now, London: HMSO

Department of Health (2001) Valuing People, London: HMSO

Descartes, R. (1640, 1968) Discourse on Method and The Meditations, London: Penguin

Deleuze, G. and Guattari, F. (1987) A thousand plateaus. London: Continuum

Edwards, S. (1998) The body as object versus the body as subject: The case of disability, Medicine, Health Care and Philosophy, 1 (1) 47-56

EHRC/Equality and Human Rights Commission (2017) Being Disabled in Britain: A journey less equal. London: EHRC

Emerson, E. and Hatton, C. (2008) People with learning disabilities in England (online). Centre for Disability Research: Lancaster University. Available at http://www.lancaster.ac.uk/staff/emersone/FASSWeb/Emerson 08 PWLDinEngland .pdf [Accessed December 2017).

Feely, M. (2016) Disability studies after the ontological turn: a return to the material world and material bodies without a return to essentialism, Disability \& Society, 31 (7) 863-883

Fitzgerald, C. and Withers, P. (2013) 'I don't know what a proper woman means': what women with intellectual disability think about sex, sexuality and themselves, British Journal of Learning Disabilities, 14 (1) 5-12

Foucault, M. (2001) Madness and Civilisation: A History of Insanity in the Age of Reason. London: Routledge Classics

Fyson, R. (2015) Building an Evidence Base for Adult Safeguarding? Problems with the Reliability and Validity of Adult Safeguarding Databases, British Journal of Social Work, 45 (3) 932-948

Fyson, R. \& Cromby, J. (2013) Human Rights and Intellectual Disabilities in an era of 'Choice' Journal of Intellectual Disability Research, 57 (12) 1164-1172 
Fyson, R. \& Kitson, D. (2007) Independence or Protection - does it have to be a choice?: Reflections on the abuse people with learning disabilities in Cornwall. Critical Social Policy, 27 (3) 426-436

Garland-Thompson, R. (2003) Integrating Disability, Transforming Feminist Theory, NWSA Journal, 14 (3) 1-32

Gates, B. and Mafuba, K. (2016) Use of the term 'learning disabilities' in the United Kingdom: Issues for international researchers and practitioners. Learning Disabilities: A Contemporary Journal, 14 (1) 9-23

Goodley, D. (2007) Becoming rhizomatic parents: Deleuze, Guattari and disabled babies, Disability \& Society, 22 (2) 145-160

Goodley, D. (2011) Disability Studies: An Interdisciplinary Introduction. London: Sage

Goodley, D. (2014) Dis/ability Studies. Theorising disableism and ableism, London: Routledge.

Goodley, D. (2011) Self-advocacy in the lives of people with learning disabilities. Maidenhead: Open University Press

Haigh, A. Lee, D. Shaw, C. Hawthrone, M. Chambelain, S. Newman D.W, Clark, Z. and Beail, N. (2013) What Things Make People with a Learning Disability Happy and Satisfied with Their Lives: An Inclusive Research Project. Journal of Applied Research in Intellectual Disabilities, 26 (1) 26-33

Her Majesty's Stationary Office (HMSO) (2017) Care and support statutory guidance (online) Available at https://www.gov.uk/government/publications/care-actstatutory-guidance/care-and-support-statutory-guidance [Accessed December 2017]

Her Majesty's Stationary Office (HMSO) (2014) The Care Act 2014, London: HMSO

Heywood, P. (2017) The Ontological Turn, Cambridge Encyclopaedia of Anthropology http://www.anthroencyclopedia.com/entry/ontological-turn

Hughes, B. (2004) 'Disability and the Body' in Swain, J. et al (eds) Disabling barriers Enabling environments, London, Sage

Hughes, B. and Paterson, K. (1997) The Social Model of Disability and the Disappearing Body: Towards a sociology of impairment, Disability \& Society, 12 (3) 325-340

Klotz, J. (2004) Sociocultural study of intellectual disability: moving beyond labelling and social constructionist perspectives. British Journal of Learning Disability, 32 (2) 93104

Leder, D. (1990) The Absent Body, Chicago: University of Chicago Press

McLaughlin, J. and Goodley, D. (2008) Seeking and Rejecting Certainty: Exposing the Sophisticated lifeworlds of Parents of Disabled Babies, Sociology, 42 (2) 317-335 
Theorising disability

Merleau-Ponty, M. (1964) The Primacy of Perception, Illinois: Northwestern University Press

Mladenov, T. (2014) Critical Theory and Disability, London: Bloomsbury Academic

Morgan, A. (2008), Being Human: Reflections on Mental Distress in Society, Ross -on- Wye: PCCS Books

Morris, J. (1997) Care or Empowerment? A disability Rights Perspective, Social Policy and Administration, 3 (1) 54-60

Nail, T. (2017) What is an assemblage? SubStance, 46 (1) 21-37

Nettleton, S. and Watson, J. (1998) The body in everyday life, London: Routledge

Oliver, M. (1990) The Politics of Disablement, London: Macmillan.

Palecek, M. and Risjord, M. (2012) Relativism and the ontological turn within anthropology. Philosophy of the social sciences, 43 (1) 2-23

Pilnick, A., Clegg, J., Murphy, E. and Almack, K. (2010) Questioning the answer: questioning style, choice and self-determination in interactions with young people with intellectual disabilities. Sociology of Health and Illness, 32 (3) 415-436

Povee, K. Bishop, B.J. and Roberts, L.D. (2014) The uses of photovoice with people with intellectual disabilities: reflections, challenges and opportunities. Disability \& Society, 29 (6) 893-907

Purcal, C., Fisher, K.R. and Laragy, C. (2014) Shifts in the model of service delivery in intellectual disability in Victoria, Australian Journal of Public Administration, 73 (1) 88-102

Rapley, M. (2004) The Social Construction of Intellectual Disability. Cambridge: Cambridge University Press.

Redley, M. and Weinberg, D. (2007) Learning disability and the limits of liberal citizenship: interactional impediments to political empowerment, Sociology of Health and Illness, 29 (5) 767-786

Shakespeare, T. (2014) Disability Rights and Wrongs Revisited. London: Routledge

Shildrick, M. (2015) "Why should our bodies end at the skin?": Embodiment, boundaries and somatechnics. Hypatia, 30 (1) 13-29

Thomas, C. (2004) 'Disability and impairment', in Swain, J. et al (eds) Disabling barriers Enabling environments, London: Sage

Turner, B. (2008) $3^{\text {rd }}$ ed, The Body \& Society, London: Sage

Walmsley, J. and Johnson, K. (2003) Inclusive Research with People with Learning Disabilities. Past, Present and Futures, London: Jessica Kingsley Publishers 
Watson, N. and Cunningham-Burley, S. (eds)(2001) Reframing the Body, Hampshire: Palgrave.

Wendell, S. (1996) The Rejected Body. New York: Routledge.

Werner, S. (2012) Individuals with Intellectual Disabilities: A Review of the Literature on Decision-Making since the Convention on the Rights of People with Disabilities (CRPD) Public Health Reviews, 34 (2) 1-27

Williams, S.J. and Bendelow, G. (1998) The Lived Body. Sociological Themes, Embodied Issues, London: Routeledge

Williams, V. and Simons, K. (2005) More researching together: the role of nondisabled researchers in working with People First Members, 33 (1) 6-14

Young, I.M. (1980) Throwing like a girl. A phenomenology of feminine body comportment motility and spatiality. Human Studies, 3 (2) 137-156 